\title{
Original
}

\section{Properties of wood plasticization with octanoyl chloride in a solvent-free system}

\author{
J.-H. Wu, T.-Y. Hsieh, H.-Y. Lin, I.-L. Shiau, S.-T. Chang
}

\begin{abstract}
Diffuse reflectance Fourier transform infrared spectroscopy (DRIFT), solid state cross-polarization/magic-angle-spinning ${ }^{13} \mathrm{C}$-nuclei magnetic resonance spectroscopy (CP/MAS ${ }^{13} \mathrm{C}$-NMR), X-ray diffraction (XRD), thermogravimetric analysis (TGA), and thermomechanical analysis (TMA) were used in this study to elucidate the characteristics of wood sawdust after esterification. Results revealed that thermoplastic wood was produced by solvent-free esterification using octanoyl chloride. Increasing the duration of treatment enhanced the extent of esterification. After octanoylation, the crystallinity of wood sawdust was decreased, whereas thermoplasticity, hydrophobicity, and thermal stability were enhanced. The complete flow of the octanoylated wood meal was achieved at around $300^{\circ} \mathrm{C}$ under a force of $0.01 \mathrm{~N}$, indicating that octanoylated wood sawdust is a good thermoplastic material.
\end{abstract}

\section{Introduction}

Owing to the gradual depletion of global forest resources, innovative use and recycling of natural materials is greatly needed for environmental conservation and sustainable management of natural resources. There are many by-products (wood shavings and sawdust) in the wood-processing industry. Therefore, one of

Received: 28 March 2002

Published online: 11 February 2004

(C) Springer-Verlag 2004

J.-H. Wu, S.-T. Chang $(\bowtie)$

Department of Forestry, National Taiwan University, 106 Taipei, Taiwan

E-mail: peter@ntu.edu.tw

Tel.: +886-2-23630231 ext. 3196

Fax: $+886-2-23654520$

T.-Y. Hsieh, H.-Y. Lin

Experimental Forest, National Taiwan University, 557, Nantou, Taiwan

I.-L. Shiau

Taiwan Forestry Bureau, Council of Agriculture, Executive Yuan, 100, Taipei, Taiwan

This study was supported by a grant from the Council of Agriculture (COA). The authors wish to thank the COA for financial support and the sawmill of the experimental forest of National Taiwan University for providing sugi sawdust. 
the unprecedented challenges in the wood products industry is how to improve the properties and performance of the wood products using the woody residues and how to recycle them. Among the known methods of wood utilization, wood plasticization is capable of becoming one with potential.

Plasticization of wood sawdust can be obtained either with wood-plastic composites (WPC) or by chemical modifications. In the former method, however, a major problem is the incompatibility between a natural fiber and thermoplastic polymers. Many problems have been identified including poor dispersion of the fiber due to intermolecular hydrogen bonding (Raj et al. 1989), and wide polarity differences of the surfaces preventing efficient polymer-fiber bonding (Maldas et al. 1989). To date, several physical and chemical approaches have been used to overcome these problems. One of these approaches is chemical modification which not only improves the thermoplasticity of wood (Morita and Sakata 1986; Shiraishi 1991; Nakano 1994), but also increases dimensional stability, as well as fire and decay resistance (Rowell 1983; Engonga et al. 1999).

Shiraishi et al. (1979a) reported that the thermofluidity was observed when wood samples esterified with appropriate acid chlorides in $\mathrm{N}_{2} \mathrm{O}_{4}$-dimethylformamide- pyridine medium, and that increasing the chain length of the alkyl substituent led to a decrease in the apparent melting temperature. In general, the esterification agents must contain at least six atoms of carbon to improve the thermoplastic properties of wood (Shiraishi et al. 1979b). Besides conventional anhydrides, e.g., trifluoroacetic acid anhydride (Nakano 1994), maleic anhydride (Kazayawoko et al. 1998), maleic anhydride modified polypropylene (MAPP) (Takase and Shiraishi 1989), and styrene-maleic anhydride (SMA) (Simonsen 1998), recent progress has allowed the esterification of lignocellulosic materials with fatty acid chlorides without any base or solvent to remove gaseous acid chloride from the reaction system by applying a nitrogen stream (Thiebaud and Borredon 1995; Thiebaud et al. 1997) or vacuum (Kwatra et al. 1992). Those solvent-free reaction systems not only reduce the solvent used, but also lessen environmental pollution. Furthermore, the fatty acid cellulose esters (FACE) have been identified as potential biodegradable plastics (Kwatra et al. 1992). Therefore, it is worthy to investigate further the plasticization of woody residues using the long chain fatty acid chloride in a solvent-free system.

Sugi (Cryptomeria japonica D. Don), a fast growing Japanese cedar, is one of the important plantation tree species grown in Taiwan. Unfortunately, owing to the color variations of the different forms of sugi and the susceptibility of its heartwood to discoloration induced by environmental factors (Abe et al. 1994; Abe and Oda 1994; Takahashi 1996, 1998; Kubo and Ataka 1998; Chang et al. 2000), use of sugi solid wood in Taiwan is often restricted. Thus, to date, how to utilize sugi is a major challenge for the forestry and wood industry. Research breakthroughs in exploring the utilization methods of sugi wood of different forms, e.g., low-quality wood, wood shavings and even sawdust, are imperative.

The purpose of this study is to find appropriate treatment conditions to convert the sugi sawdust into thermally meltable materials by solvent-free octanoylation under a nitrogen stream. Furthermore, the properties of esterified wood are also investigated by using various spectrometric techniques. 


\section{Experimental}

\section{Materials}

Sugi sawdust (Cryptomeria japonica D. Don) (60-80 mesh) was obtained from the sawmill of the experimental forest of the National Taiwan University.

It was used after extraction of soluble fractions in a Soxhlet apparatus for $24 \mathrm{~h}$ with a 1:2(v/v) mixture of ethanol and toluene followed by washing with distilled water and then dried at $105^{\circ} \mathrm{C}$ for $12 \mathrm{~h}$.

Octanoyl chloride was purchased from Sigma Chemical (St. Louis, MO). The other chemicals and solvents used in this experiment were of the highest quality available.

\section{Octanoylation}

Two grams of dried sugi sawdust and $0.3 \mathrm{~mol}$ of octanoyl chloride were successively introduced into the reactor. The reaction was then conducted at $130^{\circ} \mathrm{C}$ with stirring for 1,2 , and $4 \mathrm{~h}$, respectively. To trap the hydrogen chloride formed during the reaction, a continuous nitrogen stream $(200 \mathrm{ml} / \mathrm{min})$ was applied into the reactor and a wash-bottle containing an aqueous saturated sodium hydroxide solution was placed at the outlet of the condenser. At the end of octanoylation, the esterified wood was washed with $50 \mathrm{ml}$ of ethanol and then Soxhlet-extracted using ethanol for $6 \mathrm{~h}$ to remove the excess and residues of acid chloride. Finally, the esterified wood was dried at $105^{\circ} \mathrm{C}$ for $12 \mathrm{~h}$, and weight percent gain (WPG) was then calculated.

\section{Color measurement}

The color of wood sawdust was measured with a color and color difference meter (Dr. Lange Co., Germany) using a $\mathrm{D}_{65}$ light source. The tristimulus values $X, Y$, and $Z$ of all specimens were obtained directly from the colorimeter. Then the recommended CIE (Commission Internationale d'Eclairage) $L^{*}, a^{*}$ and $b^{*}$ color parameters were computed, followed by calculating $\Delta a^{*}$ (difference of a component), $\Delta b^{*}$ (difference of $b^{*}$ component), and $\Delta C^{*}$ (chroma difference) with the following formulae (Chang 1986, 1997).

$\Delta a^{*}=a_{\mathrm{t}}^{*}-a_{\mathrm{s}}^{*}$

$\Delta b^{*}=b_{\mathrm{t}}^{*}-b_{\mathrm{s}}^{*}$

$\Delta C^{*}=C_{\mathrm{t}}^{*}-C_{\mathrm{s}}^{*}$

where $a_{\mathrm{t}}^{*}, b_{\mathrm{t}}^{*}$, and $C_{\mathrm{t}}^{*}=a^{*}, b^{*}$, and $C^{*}$ of the treated sample, respectively; $a_{\mathrm{s}}^{*}, b_{\mathrm{s}}^{*}$, and $C_{s}^{*}=a^{*}, b^{*}$, and $C^{*}$ of the control reference, respectively; $L^{*}=$ the value on the white/black axis, $a^{*}=$ the value on the red/green axis, $b^{*}=$ the value on the blue/ yellow axis, $C^{*}=$ chroma $=\left[\left(a^{*}\right)^{2}+\left(b^{*}\right)^{2}\right]^{1 / 2}$.

\section{DRIFT spectroscopy analysis}

The chemical structure analysis of esterified wood powder was carried out using diffuse reflectance Fourier transform infrared spectroscopy (DRIFT). The spectra were obtained on a Bio-rad FTS-40 (USA). Data were collected from $400 \mathrm{~cm}^{-1}$ to $4000 \mathrm{~cm}^{-1}$ with 64 scans for each sample. The resolution was $4 \mathrm{~cm}^{-1}$. 


\section{X-ray diffraction measurement}

$\mathrm{X}$-ray diffractograms were obtained with powder samples. A MAC science M03XHF analyzer (Japan) was used. The diffraction patterns were measured from $2 \theta=2$ to $35^{\circ}$ using $\mathrm{CuK} \alpha_{1}$ radiation at $40 \mathrm{kV}$ and $30 \mathrm{~mA}$.

\section{Solid state CP/MAS ${ }^{13}$ C-NMR analysis}

Solid state of the wood samples were examined by CP/MAS ${ }^{13} \mathrm{C}-\mathrm{NMR}$. The spectra were recorded on a Bruker DMX-300 FT-NMR spectrometer (Germany), at a frequency of 75.5 MHz. Chemical shifts were calculated relative to TMS for NMR control.

\section{Thermal properties}

A TA TGA-2950 thermogravimetric analyzer (USA) was used to study the thermal properties of esterified wood. The heating rate was set at $20^{\circ} \mathrm{C} / \mathrm{min}$ and the temperature ranged from 25 to $600^{\circ} \mathrm{C}$. Measurements on $5 \mathrm{mg}$ samples were carried out in a nitrogen atmosphere $(100 \mathrm{ml} / \mathrm{min})$.

In addition, a TA TMA-2940 thermomechanical analyzer (USA) was used to evaluate the softening temperature of octanoylated wood sawdust. The wood samples (approximately $6-10 \mathrm{~mm}$ in size) were run in a quartz glass vial using the dilatometer probe. Nitrogen with a flow rate of $100 \mathrm{ml} / \mathrm{min}$ was used as a purge gas, and the experimental conditions included a temperature range of 25 to $350^{\circ} \mathrm{C}$, a heating rate of $1^{\circ} \mathrm{C} / \mathrm{min}$, and a force of $0.01 \mathrm{~N}$.

\section{Results and discussion}

\section{Effects of octanoylation on the chemical structure of wood}

To understand the chemical change of sugi wood sawdust before and after octanoylation, a DRIFT spectroscopy and a CP/MAS ${ }^{13} \mathrm{C}-\mathrm{NMR}$ spectrometer were used. The results showed that, after octanoylation, the intensity of the absorption band of $\mathrm{O}-\mathrm{H}$ stretching vibration $\left(3353 \mathrm{~cm}^{-1}\right)$ was reduced by increasing the reaction time (Fig. 1), whereas those of $\mathrm{C}=\mathrm{O}\left(1749 \mathrm{~cm}^{-1}\right)$ and $\mathrm{C}-\mathrm{O}\left(1166 \mathrm{~cm}^{-1}\right)$ bands were increased. When the reaction duration was $4 \mathrm{~h}$, the absorption peak of hydroxyl groups almost disappeared (Fig. 1D), elucidating that acyl groups had substituted for the hydrogen atoms of the hydroxyl groups of wood sawdust. In addition, the intensity of methyl and methylene groups at $3000-2840 \mathrm{~cm}^{-1}$ increased significantly after octanoylation in which C-H symmetrical stretching $\left(v_{\mathrm{s}}\right)$ and asymmetrical stretching $\left(v_{\mathrm{as}}\right)$ bands including $2958 \mathrm{~cm}^{-1}\left(v_{\mathrm{s}} \mathrm{CH}_{3}\right), 2930 \mathrm{~cm}^{-1}\left(v_{\mathrm{s}} \mathrm{CH}_{2}\right), 2871 \mathrm{~cm}^{-1}\left(v_{\mathrm{as}} \mathrm{CH}_{3}\right)$, and $2858 \mathrm{~cm}^{-1}$ $\left(v_{\text {as }} \mathrm{CH}_{2}\right.$ ) could be clearly distinguished. Meanwhile, the intensities of $\mathrm{C}-\mathrm{H}$ bending vibrations, such as $1462 \mathrm{~cm}^{-1}\left(\delta_{\mathrm{s}} \mathrm{CH}_{2}\right), 1379 \mathrm{~cm}^{-1}\left(\delta_{\mathrm{s}} \mathrm{CH}_{3}\right)$, and $724 \mathrm{~cm}^{-1}\left(\rho \mathrm{CH}_{2}\right)$, were also enhanced. In general, the band resulting from the methylene rocking vibration $\left(\rho \mathrm{CH}_{2}\right)$, in which all of the methylene groups in phase, appears at about $720 \mathrm{~cm}^{-1}$ for straight-chain alkanes of seven or more carbon atoms (Silverstein et al. 1991). Thus, it indicated that octanoylation had indeed occurred when the sugi sawdust reacted with octanoyl chloride under a solvent-free system.

Furthermore, to understand the effects of reaction time on esterification, the absorption intensity of $1510 \mathrm{~cm}^{-1}$ was used as an internal standard. The ratios of the intensity of peak at $3353 \mathrm{~cm}^{-1}$ to $1510 \mathrm{~cm}^{-1}$ calculated for $0,1,2$, and $4 \mathrm{~h}$ of reaction were $1.8,0.6,0.1$, and 0.0 , respectively (Table 1 ). These data demonstrated that the contents of $\mathrm{O}-\mathrm{H}$ of wood sawdust were decreased by prolonging 


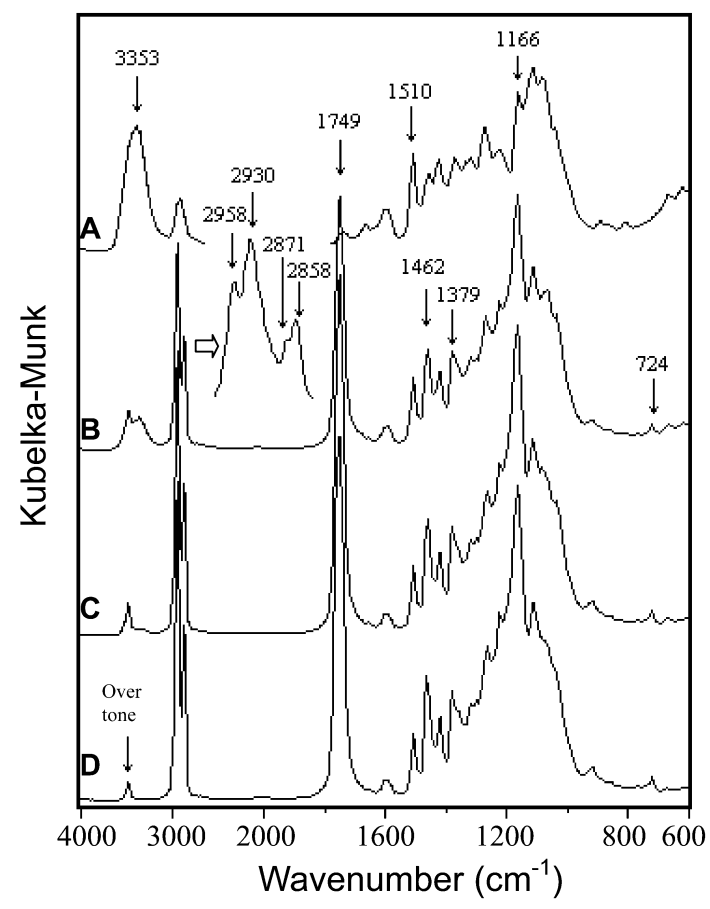

Fig. 1. DRIFT spectra of wood sawdust treated with octanoyl chloride for various time. A control; B 1 h; C 2 h; D 4 h

the reaction time (Table 1), whereas the relative intensities of $2930 \mathrm{~cm}^{-1}(\mathrm{C}-\mathrm{H})$ and $1749 \mathrm{~cm}^{-1}(\mathrm{C}=\mathrm{O})$ as well as the WPG were increased. It indicated that increasing reaction time enhanced the extent of octanoylation. The highest esterification $(\mathrm{WPG}=86.5$ ) was achieved when the reaction time was $4 \mathrm{~h}$.

On the other hand, the ${ }^{13} \mathrm{C}$-NMR spectra of wood sawdust showed that the peaks at 13.7, 22.6, 24.6, 29.3, 31.8, 32.8, and $33.6 \mathrm{ppm}$, all of which belong to straight-chain alkanes of seven carbons, were substantially observed after octanoylation (Fig. 2B). Moreover, a peak at $172.1 \mathrm{ppm}$, assigned to the octanoyl group $\left(\mathrm{CH}_{3}\left(\mathrm{CH}_{2}\right)_{6} \mathrm{CO}-\right)$, was also found in Fig. 2B. These data confirmed further that the sugi sawdust was octanoylated after being treated with octanoyl chloride. In addition, Fig. 2A showed a characteristic carbohydrate pattern, namely $\mathrm{C} 1$ (104.7 ppm), C4 (88.6 ppm and 83.5 ppm), C2 (74.6 ppm), C3, C5 (71.9 ppm), and C6 (65.1 ppm and $62.1 \mathrm{ppm})$. However, after octanoylation, the intensities of

Table 1. Relative intensity of DRIFT absorption peaks and weight percent gain for octanoylated wood sawdust

\begin{tabular}{|c|c|c|c|c|}
\hline \multirow{2}{*}{$\begin{array}{l}\text { Reaction time } \\
\text { (h) }\end{array}$} & \multicolumn{3}{|l|}{ Relative intensity } & \multirow[t]{2}{*}{ WPG } \\
\hline & $\mathrm{A}_{3353 \mathrm{~cm}^{-1} / 1510 \mathrm{~cm}^{-1}}$ & 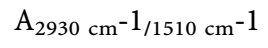 & 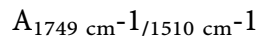 & \\
\hline Control & 1.8 & 0.6 & 0.2 & - \\
\hline 1 & 0.6 & 3.9 & 4.8 & 37.5 \\
\hline 2 & 0.1 & 5.5 & 7.0 & 72.6 \\
\hline 4 & 0.0 & 6.4 & 7.3 & 86.5 \\
\hline
\end{tabular}




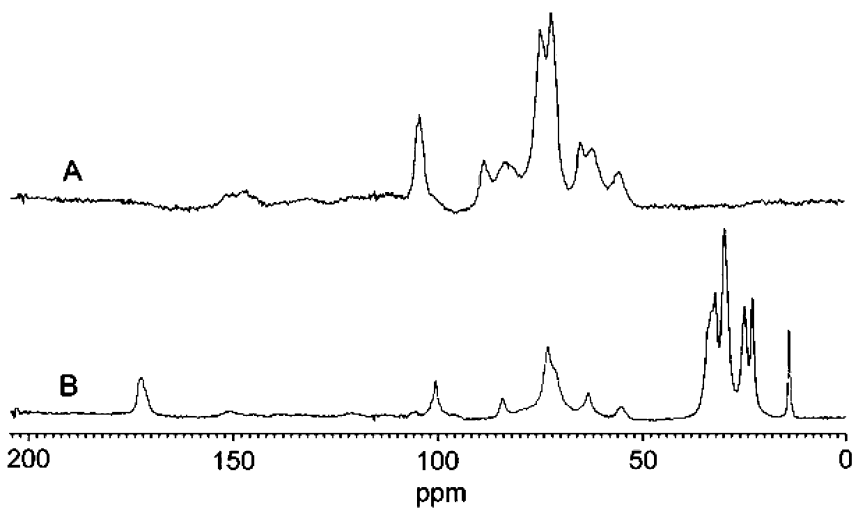

Fig. 2. Solid state CP/MAS ${ }^{13} \mathrm{C}-\mathrm{NMR}$ spectra of wood sawdust before (A) and after (B) esterification with octanoyl chloride for $2 \mathrm{~h}$

peaks at $88.6 \mathrm{ppm}$ (crystalline C4) and $65.1 \mathrm{ppm}$ (crystalline C6) were decreased and shifted to $84.1 \mathrm{ppm}$ (amorphous C4) and $63.0 \mathrm{ppm}$ (amorphous C6), respectively. These results indicated that cellulose in wood was decrystallized after treatment with octanoyl chloride, a long-chain acid chloride. Furthermore, the diffraction patterns of wood sawdust before and after octanoylation were obtained by using an XRD analyzer. As shown in Fig. 3, there were two diffraction rays for $2 \theta=22^{\circ}$ and $15^{\circ}$ before treatment, by which the calculated crystallinity index (CrI) was $43.3 \%$. After octanoylation, the former ray due to the 002 plane of crystal lattice was shifted to the amorphous of $19.6^{\circ}$, and the other ray corresponding to the reflection of planes 101 and $10 \overline{\overline{1}}$ of the native cellulose lattice vanished and a new peak appeared at $2 \theta=4.1^{\circ}$ (Fig. $3 B, C, D$ ). These results are similar to the spectra obtained by Thiebaud et al. (1997). The peak of crystalline phase could not be observed after octanoylation, and the extent of decrystallization was a function of ester content (or WPG). This indicated that prolonging

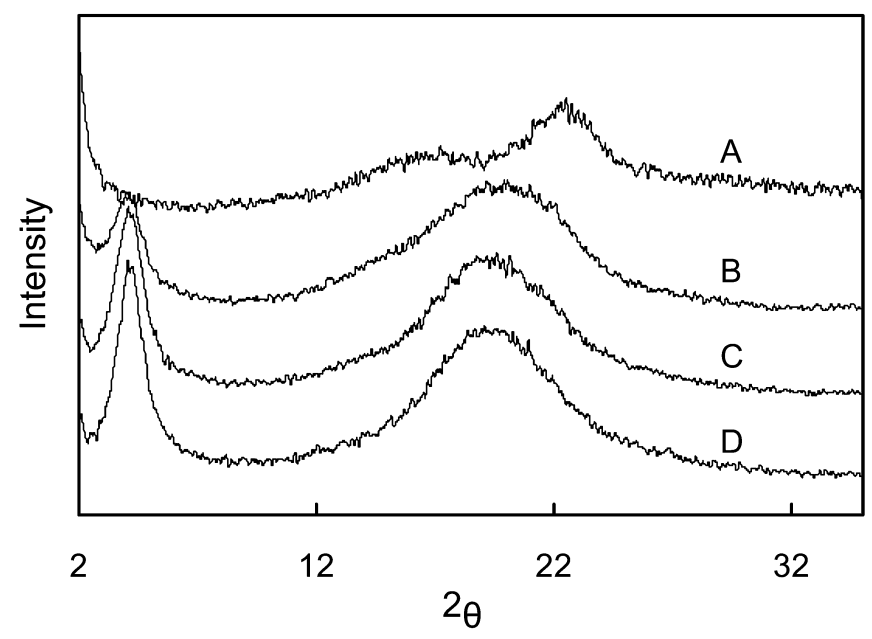

Fig. 3. X-ray diffraction diagrams of wood sawdust treated with octanoyl chloride for various time. A control; B $1 \mathrm{~h}$; C $2 \mathrm{~h}$; D $4 \mathrm{~h}$ 
the reaction time increased the amorphous regions of cellulose, thus prompting reagents to react with new hydroxyl groups of those regions and enhance the accessibility.

\section{Effects of octanoylation on the color of wood sawdust}

Table 2 shows the CIE $L^{*}, a^{*}$, and $b^{*}$ color parameters of wood sawdust before and after octanoylation. As can be seen, $a^{*}$ and $b^{*}$ values of wood sawdust were not significantly different from those of several octanoylated ones whose $\Delta a^{*}$ and $\Delta b^{*}$ values were in the range of 1.6-2.1 and 1.6-2.8, respectively. In other words, there was almost no influence on the hue of wood sawdust after treatment with octanoyl chloride. As for the lightness $\left(L^{*}\right)$ and chroma of wood sawdust, as shown in Table 2 , the chroma increased slightly $\left(\Delta C^{*}=2.3\right.$ to 3.1$)$, whereas the $L^{\star}$ value reduced from 70.3 to $61.2-63.4$ after octanoylation. These results indicate that the color of esterified wood sawdust becomes slightly less bright than that of untreated sawdust.

\section{Effects of octanoylation on the thermal properties of wood sawdust}

To evaluate the thermal properties of wood sawdust after octanoylation, a thermogravimetric analyzer and a thermomechanical analyzer were used. The thermogravimetric analysis (TGA) of wood sawdust treated with octanoyl chloride for various durations is shown in Fig. 4. The TGA of untreated wood sawdust (Fig. 4A) indicated a water loss of $3.9 \%$ between 25 and $200^{\circ} \mathrm{C}$. A water loss of less than $1 \%$ was obtained over the same temperature range for octanoylated ones.

Table 2. Color variations of wood sawdust after esterification with octanoyl chloride

\begin{tabular}{lllllll}
\hline Reaction time (h) & \multicolumn{2}{l}{ CIE LAB } & & $\Delta a^{*}$ & $\Delta b^{*}$ & $\Delta C^{*}$ \\
\cline { 2 - 5 } & $L^{*}$ & $a^{*}$ & $b^{*}$ & & & \\
\hline Control & 70.3 & 8.5 & 23.0 & - & - & - \\
1 & 61.2 & 10.6 & 24.6 & 2.1 & 1.6 & 2.3 \\
2 & 63.4 & 10.1 & 25.4 & 1.6 & 2.4 & 2.8 \\
4 & 61.2 & 10.1 & 25.8 & 1.6 & 2.8 & 3.1 \\
\hline
\end{tabular}

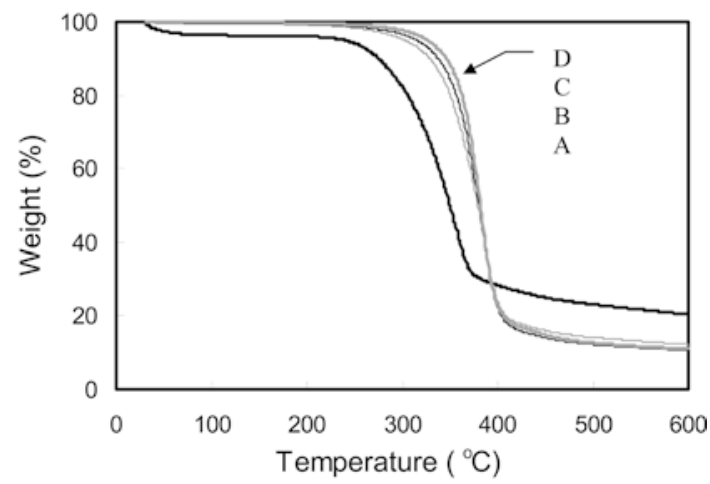

Fig. 4. Thermogravimetric analysis of wood sawdust treated with octanoyl chloride for various time. A control; B $1 \mathrm{~h} ; \mathrm{C} 2 \mathrm{~h}$; D $4 \mathrm{~h}$ 
This could be accounted for by the increased hydrophobicity of wood sawdust after octanoylation because the hydroxyl groups of crystalline and amorphous regions of wood sawdust were replaced by the hydrophobic acyl groups $\left(\mathrm{CH}_{3}\left(\mathrm{CH}_{2}\right)_{6} \mathrm{CO}-\right)$.

In general, the temperature of wood pyrolysis was over $200^{\circ} \mathrm{C}$ (Fengel and Wegener 1989). Indeed, on the TGA curve for the untreated wood (Fig. 4A), the weight loss increased gradually at temperatures above $200^{\circ} \mathrm{C}$. A maximum weight loss was obtained when the temperature was around $350^{\circ} \mathrm{C}$. In contrast, the temperature of maximum weight loss increased about $30^{\circ} \mathrm{C}$ after octanoylation (Table 3). These observations showed that octanoylation enhanced the thermostability of wood. In addition, comparisons of the amount of carbonized residue at $600^{\circ} \mathrm{C}$, before and after octanoylation as shown in Table 3, indicated that $20.4 \%$ carbonized residue was obtained from the untreated sawdust, and was less than $13 \%$ for octanoylated ones. These results suggested that the acyl groups in the octanoylated wood were eliminated with the volatile products and did not contribute to the carbonized residue.

On the other hand, comparing the thermoplasticity of the octanoylated wood sawdust with that of the untreated one, we obtained TMA curves as shown in Fig. 5. It was obvious that no thermal softening was observed for the untreated sugi sawdust until it was heated to $250^{\circ} \mathrm{C}$. In contrast, after octanoylation, the wood sawdust began softening at about $250^{\circ} \mathrm{C}$, and showed a sharp drop due to the complete flow of the sample when the temperature reached about $300^{\circ} \mathrm{C}$. Moreover, the temperature of thermal flow of octanoylated wood decreased

Table 3. Thermal properties of wood sawdust esterified with octanoyl chloride

\begin{tabular}{llll}
\hline $\begin{array}{l}\text { Reaction time } \\
\text { (h) }\end{array}$ & \multicolumn{2}{l}{ Weight \% at } & $\begin{array}{l}\text { DTG } \\
\text { Max. Peak }\end{array}$ \\
\cline { 2 - 3 } & $200^{\circ} \mathrm{C}$ & $600{ }^{\circ} \mathrm{C}$ & \\
\hline Control & 96.1 & 20.4 & $352.9^{\circ} \mathrm{C}$ \\
1 & 99.2 & 12.2 & $384.0^{\circ} \mathrm{C}$ \\
2 & 99.4 & 10.6 & $382.3^{\circ} \mathrm{C}$ \\
4 & 99.7 & 11.0 & $381.8^{\circ} \mathrm{C}$ \\
\hline
\end{tabular}

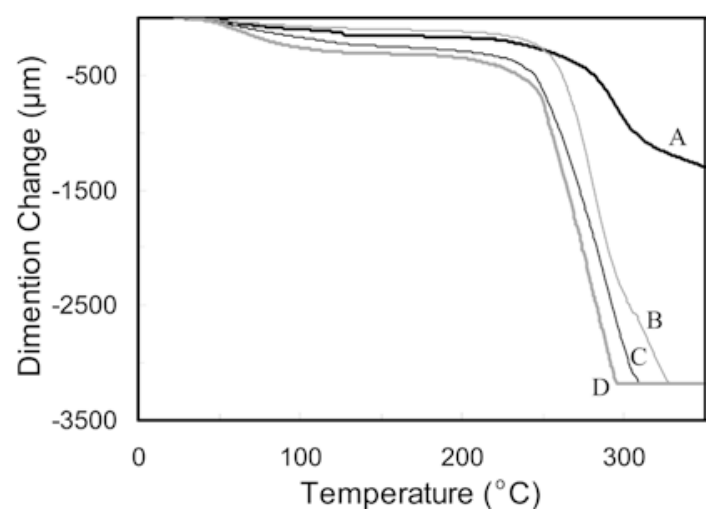

Fig. 5. Thermomechanical analysis of wood sawdust treated with octanoyl chloride for various time. A control; B $1 \mathrm{~h}$; C $2 \mathrm{~h}$; D $4 \mathrm{~h}$ 
gradually with increasing esterification time. Accordingly, the octanoylated wood sawdust possesses very good thermoplasticity indeed.

\section{Conclusions}

Wood has almost no thermoplasticity and does not thermally flow or melt. However, wood can be converted into thermoplastic materials through some types of chemical modifications. Among the various plasticization methods, solvent-free octanoylation is a good chemical process. According to the data obtained from the analyses of DRIFT, solid state ${ }^{13} \mathrm{C}-\mathrm{NMR}, \mathrm{XRD}, \mathrm{TGA}$, and TMA, prolonging the octanoylation time not only increases WPG of sugi sawdust, but also the acyl content. It is known that hydroxyl groups of wood are most often the reactive sites. When the reaction time was $4 \mathrm{~h}$, the absorption characteristics of hydroxyl groups almost disappeared. This shows that, under a solvent-free system, an excellent reactivity exists between sugi sawdust and octanoyl chloride. In addition, the brightness of octanoylated sugi sawdust is slightly less than that of the untreated one, but the decrystallization of cellulose by acylation with octanoyl chloride enhances the thermoplastic properties and thermal stability of wood, while increasing its hydrophobicity. Furthermore, complete flow of the octanoylated sugi meal was achieved at about $300^{\circ} \mathrm{C}$ under a force of $0.01 \mathrm{~N}$. Therefore, it is concluded that octanoylated wood sawdust is an excellent thermoplastic material.

\section{References}

Abe Z, Oda K (1994) The color change of sugi (Cryptomeria japonica D. Don) heartwood from reddish brown to black. II. Identification of potassium hydrogen carbonate as one of the causative materials. Mokuzai Gakkaishi 40:1126-1130

Abe Z, Oda K, Matsumura J (1994) The color change of sugi (Cryptomeria japonica D. Don) heartwood from reddish brown to black. I. The color changes and its causes. Mokuzai Gakkaishi 40:1119-1125

Chang ST (1986) Quantitative color measurement of wood. Taiwan For Res Inst Bull 471:1-14

Chang ST (1997) Comparison of the green color fastness of ma bamboo (Dendrocalamus spp.) culms treated with inorganic salts. Mokuzai Gakkaishi 43:487-492

Chang ST, Wang SY, Cheng SS (2000) Environmental effects on the color of sugi (Cryptomeria japonica D. Don) heartwood. J Wood Sci 46:390-394

Engonga PE, Schneider R, Gérardin P, Loubinoux B (1999) Chemical modification of wood with perfluoroalkyl ethanol and 4,4'-diphenylmethane diisocyanate. Holzforschung 53:272-276

Fengel D, Wegener G (1989) Influence of temperature. In: Fengel D, Wegener G (eds) Wood chemistry, ultrastructure, reaction. Walter de Gruyter, Berlin, pp 319-342

Kazayawoko M, Balatineca JJ, Woodhams RT, Sodhi RNS (1998) X-ray photoelectron spectroscopy of lignocellulosic materials treated with maleated polypropylenes. J Wood Chem Technol 18:1-26

Kubo T, Ataka S (1998) Blackening of sugi (Cryptomeria japonica D. Don) heartwood in relation to metal content and moisture content. J Wood Sci 44:137-141

Kwatra HS, Caruthers JM, Tao BY (1992) Synthesis of long chain fatty acids esterified onto cellulose via the vacuum-acid chloride process. Ind Eng Chem Res 31:2647-2651

Maldas D, Kokta BV, Daneault C (1989) Influence of coupling agents and treatments on the mechanical properties of cellulose fiber-polystyrene. J Appl Polym Sci 37:751-775

Morita M, Sakata I (1986) Chemical conversion of wood to thermoplastic material. J Appl Polym Sci 31:831-840

Nakano T (1994) Mechanism of thermoplasticity for chemically-modified wood. Holzforschung 48:318-324

Raj RG, Kokta BV, Maldas D, Daneault C (1989) Use of wood fibers in thermoplastics. VII. The effect of coupling agents in polyethylene-wood fiber composites. J Appl Polym Sci 37:10891103 
Rowell RM (1983) Chemical modification of wood. For Prod J 6:363-382

Shiraishi N (1991) Wood plasticization. In: Hon DN-S, Shiraishi N (eds) Wood and cellulosic chemistry. Marcel Dekker, New York, pp 861-906

Shiraishi N, Matsunaga T, Yokota T (1979a) Preparation of higher aliphatic acid esters of wood in an $\mathrm{N}_{2} \mathrm{O}_{4}$-DMF cellulose solvent medium. J Appl Polym Sci 24:2347-2359

Shiraishi N, Matsunaga T, Yokota T (1979b) Thermal softening and melting of esterified wood prepared in an $\mathrm{N}_{2} \mathrm{O}_{4}$-DMF cellulose solvent medium. J Appl Polym Sci 24:2361-2368

Silverstein RM, Bassler GC, Morrill TC (1991) Characteristic group absorptions of organic molecules. In: Silverstein RM, Bassler GC, Morrill TC (eds) Spectrometric identification of organic compounds, 5th ed. Wiley, New York, p 103

Simonsen J, Jacobson R, Rowell R (1998) Properties of styrene-maleic anhydride copolymers containing wood-based fillers. For Prod J 48:89-92

Takahashi K (1996) Relationships between the blacking phenomenon and norlignans of sugi (Cryptomeria japonica D. Don) heartwood. I. A case of partially black heartwood. Mokuzai Gakkaishi 42:998-1005

Takahashi K (1998) Relationships between the blacking phenomenon and norlignans of sugi (Cryptomeria japonica D. Don) heartwood. II. On blacking heartwood containing two main norlignans, sugiresinol and hydroxysugiresinol. Mokuzai Gakkaishi 44:125-133

Takase S, Shiraishi N (1989) Studies on composites and polypropylenes. J Appl Polym Sci 37:645-659

Thiebaud S, Borredon ME (1995) Solvent-free wood esterification with fatty acid chlorides. Bioresource Technol 52:169-173

Thiebaud S, Borredon ME, Baziard G, Senocq F (1997) Properties of wood esterified by fatty-acid chlorides. Bioresource Technol 59:103-107 